\title{
The use of building information modelling (BIM) in managing knowledge in construction project delivery: a conceptual model
}

\author{
T. Bouazza, C. E. Udeaja \& D. Greenwood \\ Department of Mechanical and Construction Engineering, \\ Faculty of Engineering and Environment, \\ Northumbria University, UK
}

\begin{abstract}
Today's construction environment is described as turbulent due to economic crisis, global competition and rapid changes in industry structure. For most of the construction organisations to stay afloat within this environment, organisations have to find new ways to create value for their potential and existing clients. Building information modelling (BIM) technology has been identified by many proponents in this area as the technology that can create value within the supply chain (SC). In the UK, BIM is increasingly being seen not just as a technical process to determine the likely performance of projects but a valuable tool in the mediation between many associated stakeholders with their differing visions, numerous requirements and variation in their expertise, and as a valuable process to promoting learning and managing knowledge. This emerging role presents new and considerable challenges for management of knowledge during its generation, capture and reuse to ensure the meaningful engagement of such stakeholders in the project process. This research will investigate the effective methods for Knowledge Management (KM) to be implemented in the current construction environment, using BIM as a means for managing knowledge and learning. The work presented in this paper will develop a conceptual model of how BIM can be used to manage knowledge in construction project delivery. The paper will describe the proposed conceptual model that uses BIM to manage knowledge in construction project delivery and concludes with suggestions of how this might be implemented in practice, as well as further work that is required in this area.

Keywords: KM, BIM, construction project, tier 2 supply chain, COBie.
\end{abstract}




\section{Introduction}

The construction industry plays a key role on the national scene; it occupies a fundamental position in the national economy. The construction industry is beneficial in generating employment for more than 2.8 million people and the globalization of construction works around the world [1]. According to Peters and Katalytik [2] the construction sector increases the gross domestic product GDP by $10 \%$ which contributes significantly to economic growth. However, the construction industry is becoming turbulent due to economic crisis, global competition and rapid changes in industry structure. These factors contributed to the emergence of some issues that construction organisations are facing such as spiraling costs, increasing demands for efficiency [3], fragmentation issues, and lack of collaboration among project team members $[4,5]$. This work developed here is part of a PhD research work undertaken in Northumbria University on the role of building information modelling (BIM) in managing knowledge in the construction project delivery. Current practice for research initiatives for Knowledge Management (KM) will be reviewed. This will lead to the formulation of a KM strategy that uses BIM to facilitate communication and collaboration across the supply chain (SC) in order to develop knowledge repositories and learning chains. The proposed framework is expected to enhance communication and collaboration, and avoid information loss, overload, duplication and misunderstanding. It is also anticipated that an effective KM strategy will help in preserving knowledge effectively across various stages of a construction project's delivery.

\section{Knowledge management in construction project delivery}

Construction project activities are knowledge-intensive activities which place construction organisations in the position to find ways to manage their information and knowledge more efficiently and effectively [6]. Knowledge Management (KM) is not a new concept and has been around since the early 1990s, and there have been many acknowledgments that knowledge is a company's most critical asset and a source of lasting competitive advantage [7]. In the building industry, the awareness of KM has increased considerably over the last few years. Research proponents indicated that many construction companies were aware of the benefits of KM and many more had or were planning to have a KM strategy in place. This awareness of the importance of KM has stemmed from important industry reviews [8-10]. These have all emphasised the need for change, innovation and best practice, of which KM is acknowledged to be a major component. The argument for $\mathrm{KM}$ is further reinforced by the current economic crisis that has produced challenges for the construction industry as firms who lose their intellectual assets and face a downsizing without capturing knowledge first due to lack of KM strategies. Perhaps now, more than ever the commercial advantages of KM have become relevant. KM can help to minimize waste, prevent the duplication of effort and the repetition of similar mistakes from past projects and for improved efficiency. It can also aid the reuse of existing knowledge gained via past 
experience which can greatly reduce the time spent on problem solving and increase the quality of work. In order to stay afloat within the construction environment, the organisations have to find new ways to create value and manage the knowledge of the project for their potential and existing clients. Kayaçetin and Tanyer [11] argued that knowledge is deemed as a critical factor in realising the most successful projects and the most important asset within the organisations that gained competitive advantage in the market.

According to Tan et al. [7], knowledge in a construction project is divided into three categories: general, specific, and process. The management of this knowledge is mostly informal and people-centred; however, there is a growing trend towards the development of formal strategies in place. On the other hand, in a supply chain the role of managing knowledge lies with different supply chain tiers, which requires the collaboration of many suppliers that might not be involved at the early stage of design, such as the tier 2 supply chain (see Figure 1). The tier 2 supply chain as shown in Figure 1 are those suppliers who do not have direct links with the ultimate client (the main client), but are required to contribute their knowledge at the early stage of the project. The knowledge and information that these tier 2 suppliers contribute at the early stage is hardly used and normally wasted, which leads to the repetition of mistakes, work overload, and hence to loss of the intellectual assets and competitiveness in the market. Zisko-Aksamija [12] argued that the role of managing knowledge during its generation is challenging, therefore to manage this knowledge there is a need for some effective strategies.

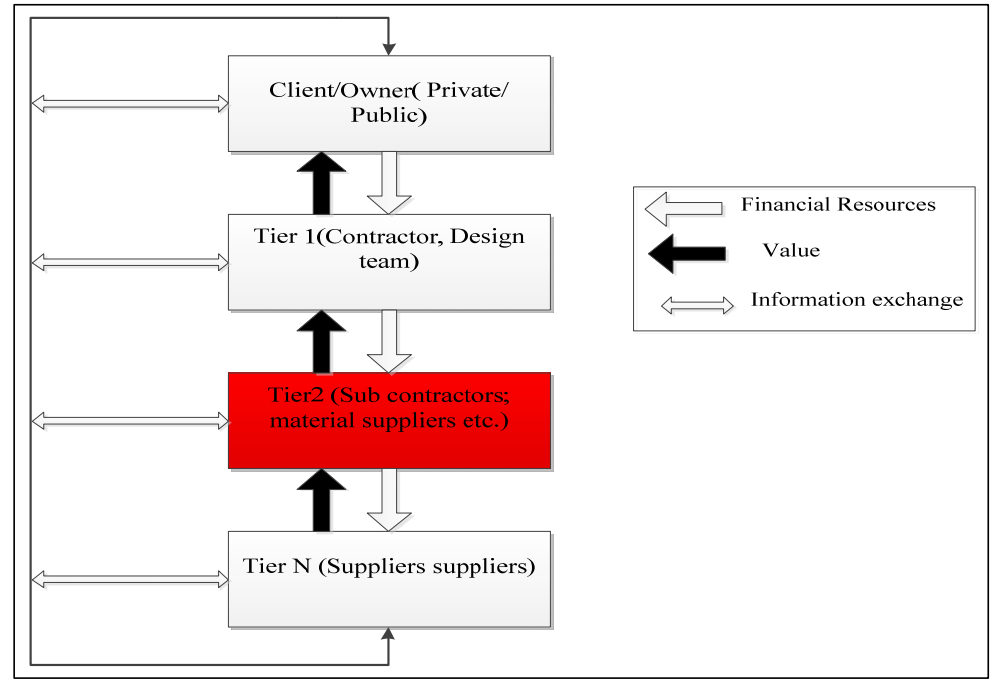

Figure 1: The relationship between suppliers.

BIM has been identified by many proponents in this area as an approach that can create value and manage knowledge within the SC [12-14]. In the UK, BIM is increasingly being seen not just as a set of technical tools and processes for improving the performance of projects but as a valuable tool in the mediation 
between many associated stakeholders with their differing visions, numerous requirements and variations in their expertise, and as a valuable process to promoting learning and managing of knowledge $[15,16]$. The next section will discuss existing using BIM processes in managing knowledge in project delivery.

\section{Potential of BIM processes in managing knowledge in project delivery}

BIM has been given many different definitions [17-21]. Most of these sources have defined BIM as a technological tool that represents a building in a three dimensional digital model and a platform where all parties involved can access and exchange information and data concerning the project. However, BIM is not only about technology, it encompasses other aspects such as the relationships between the stakeholders and the process of delivering a construction project. According to the government report by UK Treasury, BIM is a collaborative way of working between the stakeholders using the contemporary technologies that facilitate the design and construction processes [19]. Despite the different definitions of BIM, there are several on-going research projects investigating aspects of managing knowledge in construction projects delivery using BIM processes. These recent research works include the following:

- Oxman [22] discussed the possibility to move from BIM to Building Knowledge Model (BKM) that facilitates the collaboration of team members in digital design through the use of two models: the Schema Emergence in human mind and digital design and the Issue-Concept-Form (ICF) models.

- Konukcu and Koseoglu [23] demonstrated how BIM could be integrated into the construction supply chain in order to improve information flow and knowledge management between the stakeholders throughout the lifecycle of the construction project. This was called a Building Knowledge Model (BKM) through BIM technologies and human interactions.

- Liu et al. [20] developed a building knowledge modelling (BKM) approach that integrates BIM and KM to capture and reuse knowledge in BIM processes. This approach requires the integration of an intermediate module called 'Knowledge+' which is used to connect BIM with a Knowledge Management System (KMS).

- Jan et al. [24] proposed a methodology called BIM-based Knowledge Sharing Management (BIMKSM) System that enhances construction project knowledge sharing using a BIM approach. The BIMKSM approach is used as a visual platform combining a BIM approach and web technologies.

- Charlesraj [21] developed a conceptual Knowledge-based BIM (K-BIM) framework which combines BIM, KM, and Facility Management (FM) ontologies. This approach is claimed to help to facilitate the more effective management of a facility.

- Deshpande et al. [25] explored a novel method that captures knowledge during the design and construction stages utilizing the parametrics of BIM models through IFC (Industry Foundation Class) format. 
This summary of the research in this area is by no means exhaustive; however the proliferation of research projects demonstrates the increasing interest of researchers in integrating BIM and KM for improving the competitiveness of construction organisations in delivering their projects. However, construction organisations and the industry still has a significant gap to bridge to reach best practice in their use of BIM systems in managing knowledge in project delivery. It is clear that some developments are still needed to exploit the full potential of BIM in this respect. The research work on 'Building Information ModellingKnowledge Management systems' (BIM-KM system) addresses how the emerging BIM paradigm can be deployed to improve construction projects delivery.

\section{A strategy for developing a conceptual model for the use of BIM in Managing Knowledge}

This research aims to develop a new concept called 'Building Information Modelling-Knowledge Management' system (BIM-KM system), which uses BIM processes to manage Tier 2 (sub-contractors') knowledge in a construction project delivery (see Figure 1 for an illustration of Tier 2). The Tier 2 supply chains would ideally be required to contribute their knowledge and expertise at an early stage of the construction project but these suppliers or sub-contractors are normally only able or willing to contribute a fraction of their knowledge: the main reason for this is their need to avoid commercial exposure $[26,27]$. The resulting situation is that by time the contract is awarded, and the Tier 2 suppliers are in place, contractually, the unexploited knowledge is then less useful to the parties involved. This invariably leads to a missed opportunity and loss of value to the owner and a loss of competitiveness in the market for the Tier 2 suppliers (see Figure 2). What is required is a strategy that will help manage the unexploited knowledge before the value diminishes.

\section{The conceptual framework for BIM-KM}

The work presented in this paper emphasizes the use of BIM processes in order to manage and capture the Tier 2 knowledge before the value diminishes. The research proposed here will develop a framework called 'BIM-KM system' to address the issue of losing the Tier 2 knowledge as explained in the previous section. The approach will enable the construction project team using BIM platform to capture Tier 2 knowledge at the design stage of a project. The knowledge captured can then be reused in subsequent stages of the project and other construction projects contributing to the increase of the organisation assets. The framework consists of the following: a project knowledge file (e.g. COBie), an integrated BIM platform, Tier 2 knowledge that deals with knowledge and learning events and Tier 2 knowledge managers (see Figure 3). However, before these components are described, an overview of the procedure will be presented below. 


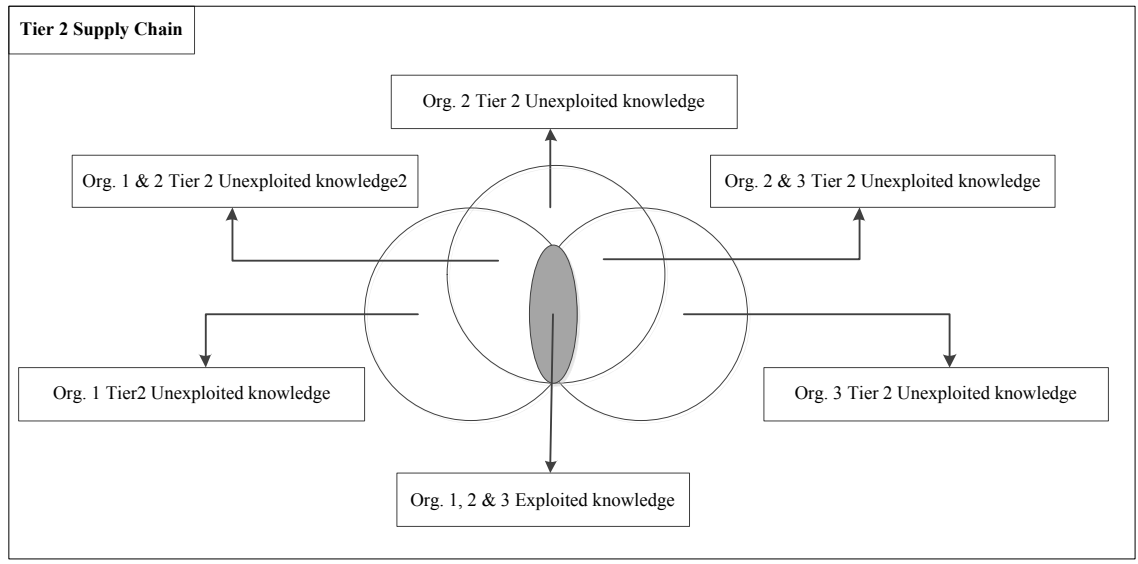

Figure 2: Knowledge loss illustration.

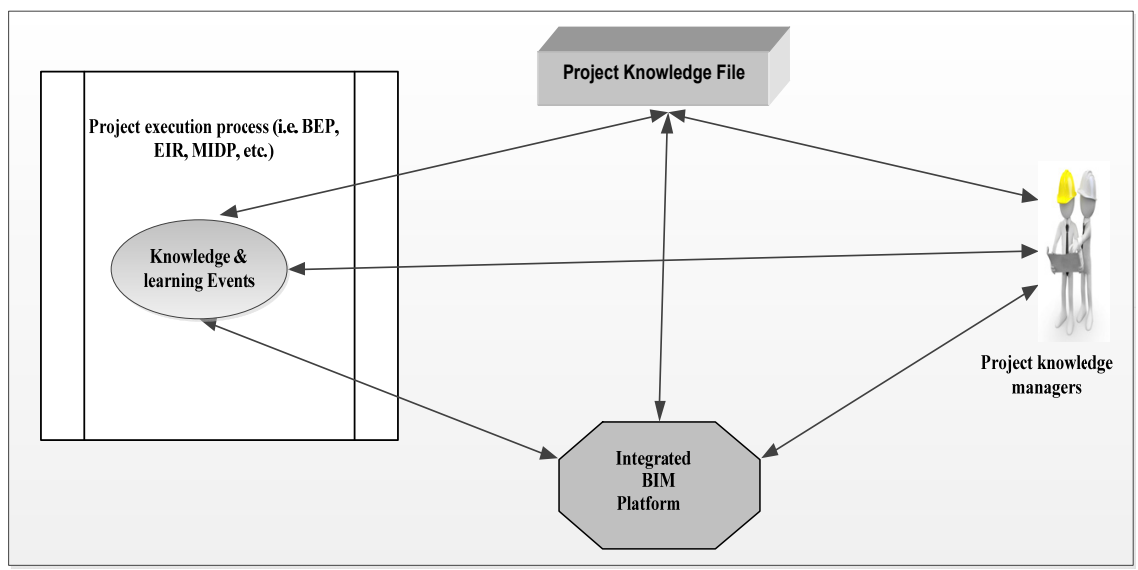

Figure 3: The conceptual framework.

\subsection{Overview of the BIM-KM system}

Figure 3 shows the overview of the BIM-KM system. During the delivery of a project, knowledge and learning events occur throughout the BIM execution and also from normal day-to-day activities. These knowledge and learning can be captured through the BIM Execution Plan (BEP), Master Information Delivery Plan (MIDP), Employer's Information Requirements (EIR), the project process or the project team involved in the project execution. The capture of these events will be facilitated using both non-digital and digital processes that will be encapsulated within the integrated BIM platform. Once the knowledge and learning are captured, they need to be stored and archived in a project knowledge file ready for reuse in the same project or subsequent projects (see Figure 3). Further works will be carried out to establish how the Tier 2 knowledge and learning events will be 
captured, organised or structured. The work that will be undertaken in this regard will utilise the PAS standards [28] in formalising and organising the knowledge and learning events. The subsequent sections will discuss the Tier 2 knowledge managers, project knowledge file and the integrated BIM platform.

\subsection{Tier 2 knowledge managers}

The role of Tier 2 knowledge managers is to manage the whole process of 'BIMKM system'. As part of this role, the knowledge managers need to be familiar with the issues around project knowledge capture and understand how to organise the knowledge and structure it for reuse. The Tier 2 knowledge managers will be in charge of developing and managing the project knowledge file and coordinating the integrated BIM platform.

\subsection{Project knowledge file}

As a prototype for the project knowledge, the project knowledge file designed for an earlier project - the CAPRIKON project [29] - was adopted. The project knowledge file will contain knowledge and information relating to both project and whole life cycle knowledge that will be used to manage the asset in the future. However, the focus will be mainly on knowledge that will be required for reuse during the project's lifecycle. In this framework, the project knowledge file will be using COBie concepts and principles for sharing non-graphic data about a building $[28,30]$. The nature and structure of the project knowledge file has not yet been determined, but conceptually the process would be that illustrated in Figure 4.

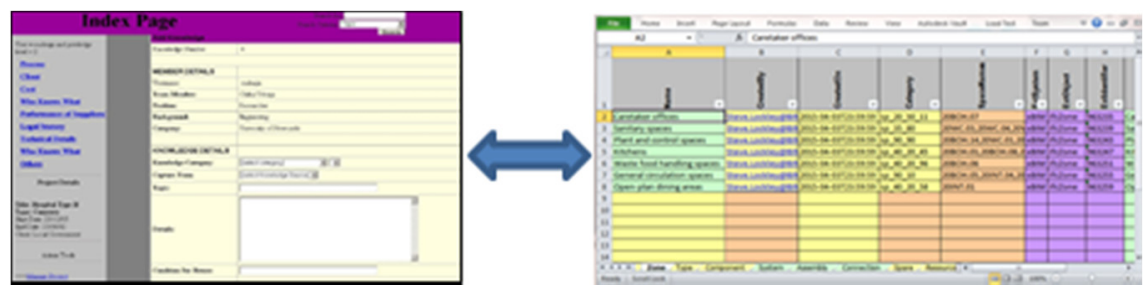

Figure 4: The project knowledge file and COBie.

\subsection{Integrated BIM platform or system}

The role of an integrated BIM platform is to capture both non-graphical and graphical data generated by the Tier 2 knowledge managers and process it in such way that the knowledge and learning events are captured and organised in the project knowledge file. The integrated BIM platform will be used to follow the information life cycle as documented by the relevant PAS standards [28]. The integrated BIM platform has been set-up in this framework to interact with the project knowledge file, the Tier 2 knowledge managers and knowledge and learning events components as shown in Figure 3. 


\section{Conclusion}

The construction industry is still facing increasing demands for efficiency and these are set against its fragmentation and lack of collaboration among the stakeholders in construction projects. In recent years, many commentators have acknowledged the need for innovation and best practice and managing knowledge has been considered to be a critical factor in realizing the most successful projects. The ability to manage the knowledge will not only help to prevent the reinvention of the wheel but will also serve as the basis for innovation and overall improvement. Given the growing importance of knowledge towards the success of a project delivery, it is not surprising that BIM champions and the construction industry are keen on developing some kind of synergy between the approaches of $\mathrm{KM}$ and BIM so that knowledge and learning chain can be created in order to unleash innovation and creativity by managing knowledge up and down supply chains. It is evident that forging a BIM and KM alliance will help provide significant opportunities to resolve many problems that exist in project delivery. As reported in this work, many previous research works on BIM and KM alliance have focused on the delivery of technology solutions, probably because of the growth in BIM technological software systems. However, it is now recognized that a good solution does not result from the implementation of information technology (IT) alone. Therefore approaches that are purely based on IT are bound to be less than successful in project delivery: process and people issues, which are not readily solved by IT systems, would need to be resolved. Thus a combined approach - one that incorporates people, process and technology - will deliver a more complete solution. The work presented in this paper, has set out an approach for using BIM in managing knowledge, which is intended to reflect people, process and technological solutions in delivering construction projects. The paper formulated a conceptual framework called 'BIM-KM system' which captures Tier 2 knowledge and learning events using an integrated BIM platform. The framework comprises of a project knowledge file, and integrated BIM platform that will help to enhance and manage Tier 2 knowledge and learning events. It is anticipated that the captured knowledge will avoid time waste, reduce cost as a result of seamless delivery, and help prevent knowledge loss due to time lapse. In the long term it will contribute in gaining competitiveness for the suppliers and value-added to the clients. Further work is required to determine the precise nature and contents of Tier 2 knowledge and learning events and how it will be organised and structured in project knowledge file before it can be reused.

\section{References}

[1] Great Britain. Parliament. House of Commons. (2008) Construction Matters: London: The Stationery Office. (HC 127-I).

[2] Peters, J., Katalytik, M. A. (2011). Equality and diversity: good practice for the construction sector.

[3] GCS (2012), Government Construction Strategy, Cabinet Office, https://www.gov.uk/government/uploads/system/uploads/attachment_data/ 
file/61151/GCS-One-Year-On-Report-and-Action-Plan-Update-FINAL 0.pdf (Accessed: 18th December, 2014).

[4] Morton, R. (2002). Construction UK Introduction to the industry. Blackwell Science Ltd.

[5] Dave, B., Koskela, L. (2009). Collaborative knowledge management - A construction case study. Automation in Construction, 18(7), pp. 894-902.

[6] Rezgui, Y., Hopfe, C. J., \& Vorakulpipat, C. (2010). Generations of knowledge management in the architecture, engineering and construction industry: An evolutionary perspective. Advanced Engineering Informatics, 24(2), pp. 219-228.

[7] Tan, H. C., Carrillo, P. M., Anumba, C. J., Bouchlaghem, N., Kamara, J. M., and Udeaja, C. E. (2007). Development of a methodology for live capture and reuse of project knowledge in construction. Journal of Management in Engineering, 23(1), pp. 18-26.

[8] Latham, M. (1994). Constructing the team: joint review of procurement and contractual arrangements in the United Kingdom construction industry: final report. HM Stationery Office.

[9] Egan, J. (1998). Rethinking construction - Report of the Construction Task Force on the Scope for Improving the Quality and Efficiency of UK Construction, DETR, London.

[10] Wolstenholme, A., Austin, S. A., Bairstow, M., Blumenthal, A., Lorimer, J., McGuckin, S., Davies, R. (2009) 'Never waste a good crisis: a review of progress since Rethinking Construction and thoughts for our future', Constructing Excellence In the Built Environment. (Online). Available at: www.constructingexcellence.org.uk (Accessed: 14 August 2014).

[11] Kayaçetin, N. C., Tanyer, A. M. (2009). Exploring knowledge management in the practice of architecture: a pilot study in the Turkish capital. METU Journal of the Faculty of Architecture, 26(2), pp. 279-307.

[12] Zisko-Aksamija, A. (2008). Knowledge Management in Architecture and Construction Industry (pp. 213-252). Santa Rosa, CA: Informing Science Press.

[13] Ganah, A., John, G. A. (2013). Suitability of BIM for enhancing value on PPP projects for the benefit of the public sector. pp. 347-356. (Online). Available at: http://clok.uclan.ac.uk/7751/1/Ganah\%20\%26\%20John\% 202013\%20PPP\%202013.pdf (Accessed: 05 May 2015).

[14] Chien, K. F., Wu, Z. H., Huang, S. C. (2014). Identifying and assessing critical risk factors for BIM projects: Empirical study. Automation in Construction, 45, pp. 1-15. (Online). Available at: http://ac.els-cdn.com/ S0926580514001071/1-s2.0-S0926580514001071-main.pdf?_tid= e53d9b34-f35b-11e4-b397-00000aacb35f\&acdnat=1430853854_4633d 2017d730c166a2e45eb1ce15b86 (Accessed: 05 May 2015).

[15] The British Standards Institution (2010) Investors report: Building information modelling (BIM). UK. (Online). Available at: http://www.hfms.org.hu/web/images/stories/BIM/FreeReport-BIM.pdf (Accessed: 20 July 2014). 
[16] Eicker, U., Weeks, R. (2014). Building information modelling as an information management tool: A South African perspective for contractors who take on design responsibility. In Management of Engineering \& Technology (PICMET), 2014 Portland International Conference on (pp. 1770-1776). IEEE.

[17] Meadati, P. (2009). BIM extension into later stages of project life cycle. In Associated Schools of Construction 45th Annual International Conference (pp. 121-129). (Online). Available at: http://ascpro0.ascweb.org/archives/ 2009/CPRT102002009.pdf (Accessed: 06 May 2015).

[18] BSA. "Frequently Asked Questions About the National BIM StandardUnited States ${ }^{\mathrm{TM}}$ ". http://www.buildingsmartalliance.org/index. $\mathrm{php} / \mathrm{nbims} / \mathrm{faq} /$ (Accessed: November 2012).

[19] Treasury, H. M. (2012). Department for Business. Innovation and Skills (BIS). (Online). Available at: www.bis.gov.uk (Accessed: 14 August 2014).

[20] Liu, F., Jallow, A.K., Anumba, Ch. J., Wu, D. (2013). Building Knowledge Modeling: integrating knowledge in BIM. (Online). Available at: http://faculty.ist.psu.edu/wu/papers/BIM-CIB-W78.pdf (Accessed: 23 April 2015).

[21] Charlesraj, V. P. C. (2014) 'Knowledge-based Building Information Modeling (K-BIM) for Facilities Management'. The 31st International Symposium on Automation and Robotics in Construction and Mining (ISARC). (Online). Available at: http://www.iaarc.org/publications/ fulltext/isarc2014_submission_104.pdf (Accessed: 23 April 2015).

[22] Oxman, R. (2009) 'Digital Design Collaboration: From BIM to BKM', in Shen, G.Q., Brandon, P., Baldwin, A. (ed.) Collaborative Construction Information Management. New York: Spon Press, pp. 92-108.

[23] Konukcu, S., Koseoglu, O. (2012) 'Knowledge Management Through BIM in Construction Supply Chains'. The 29th International Conference Beirut, Lebanon, 17-19 October. (Online). Available at: http://itc.scix.net/ data/works/att/w78-2012-Paper-79.pdf (Accessed: 23 April 2015).

[24] Jan, S. H., Ho, S. P., \& Tserng, H. P. (2013) Applications of Building Information Modeling (BIM) in Knowledge Sharing and Management in Construction. International Journal of Civil, Structural, Construction and Architectural Engineering Vol: 7, No: 11, 2013. (Online). Available at: http://www.waset.org/publications/17279 (Accessed: 23 April 2015).

[25] Deshpande, A., Azhar, S., \& Amireddy, S. (2014). A framework to leverage BIM for knowledge management in AEC projects. (Online).Available at: http://www.creative-construction-conference.com/wp-content/uploads/ 2015/01/CCC2014_A_Deshpande.pdf (Accessed: 13 April 2015).

[26] Peck, H. (2006). Reconciling supply chain vulnerability, risk and supply chain management. International Journal of Logistics: Research and Applications, 9(2), pp. 127-142. (Online). Available at: http://www.tandfonline.com/doi/pdf/10.1080/13675560600673578 (Accessed: 06 May 2015).

[27] Jüttner, U., Peck, H., \& Christopher, M. (2003). Supply chain risk management: outlining an agenda for future research. International Journal 
of Logistics: Research and Applications, 6(4), pp. 197-210. (Online). Available at: http://www.tandfonline.com/doi/pdf/10.1080/136755603 10001627016 (Accessed: 06 May 2015).

[28] The British Standards Institution (2013) Investors report: 'Specification for information management for the capital/delivery phase of construction projects using building information modelling'. PAS1192-2. Incorporating Corringendum No. 1. UK. (Online). Available at: http://www.carillion plc.com/media/105185/building_information_modelling.pdf (Accessed: 06 May 2015).

[29] Tan, H. C., Carrillo, P. M., Anumba, C. J., Bouchlaghem, N., Kamara, J. M., and Udeaja, C. E. (2007). Development of a methodology for live capture and reuse of project knowledge in construction. Journal of management in engineering, 23(1), pp. 18-26. (Online). Available at: https://dspace.lboro.ac.uk/dspace-jspui/bitstream/2134/4224/1/Carrillo\% 20ASCE\%20MinE\%202007a.pdf (Accessed: 06 May 2015).

[30] Anderson, A., Marsters, A., Dossick, C. S., Neff, G. (2012) Construction to Operations Exchange: Challenges of Implementing COBie and BIM in a Large Owner Organization. In Construction Research Congress. Construction Challenges in a Flat World (pp. 688-697). ASCE. 